\title{
Bias effects in word fragment completion in young and older adults
}

\author{
LEAH L. LIGHT \\ Pitzer College, Claremont, California \\ and \\ ROBERT F. KENNISON and MICHAEL R. HEALY \\ Claremont Graduate University, Claremont, California
}

\begin{abstract}
Young and older adults were tested on a word fragment completion task in which correct solutions were studied words, words orthographically similar to studied words, or new words. In Experiments 1 and 2, the standard production version of the word fragment completion task was used; older adults had reduced benefits of prior exposure to target words and slightly decreased costs. However, costs and benefits did not differ across age in a forced-choice version of the task (Experiment 3). At a behavioral level, the results are contrary to predictions that age differences in word fragment completion priming effects will be greater when there is a strong competitor for the correct solution and that age differences in both costs and benefits will be smaller for identification than for production tasks. Theoretical implications of these findings are considered.
\end{abstract}

It is now widely recognized that all aspects of memory for recent events are not equally sensitive to normal aging. A number of meta-analyses support this conclusion. In particular, effect sizes are generally larger for age differences in direct measures of memory that require deliberate recollection than in indirect measures of memory that tap the effects of prior experience without soliciting deliberate recollection. For instance, Verhaeghen and Salthouse (1997) reported negative correlations between age and episodic memory tasks requiring recollection, both in adults over 50 years of age (mean weighted correlation $=$ -.23 ) and in adults under 50 (mean weighted correlation = -.15). La Voie and Light (1994) found mean weighted effect sizes of 0.97 for recall and 0.50 for recognition. Similarly, Verhaeghen, Marcoen, and Goossens (1993) obtained mean weighted effect sizes of $0.99,0.91$, and 0.67 for list recall, paired-associate recall, and prose recall, respectively. In contrast to these findings for direct measures of memory, a recent meta-analysis of indirect memory tests found a mean weighted effect size of 0.185 , with a $95 \%$ confidence interval of 0.133 to 0.237 , for 95 published studies comparing young and older adults (Light,

The support of Grant AG0 2452 from the National Institute on Aging is gratefully acknowledged. We thank Marisa E. Collett and Consuelo Bingham-Mira for assistance in data collection and analysis. We also thank Yonatan Goshen-Gottstein and an anonymous reviewer, whose comments helped us to sharpen our thinking on several points. R. F. K. is now at the University of Southern California, Andrus Gerontology Center, Suite 346b, Los Angeles, CA 90089-0191.Correspondence concerning this article should be addressed to L. L. Light, Department of Psychology, Pitzer College, 1050 N. Mills Avenue, Claremont, CA 91711 (e-mail: llight@ hal.pitzer.edu).
Prull, La Voie, \& Healy, 2000). This is a relatively small effect size (Cohen, 1988).

The results of these meta-analyses would appear to strongly support the generalization that performance on indirect measures of memory declines little with age. As with all generalizations, however, caution in interpretation is needed. We believe that a caveat is in order here. The tasks included in meta-analyses of indirect measures of memory have typically involved examination of the benefits of prior experience on performance, a phenomenon known as priming. Priming is generally manifested by the increased probability of giving a correct response on some task or by decreased response latency. Word fragments may be completed more often by particular target words, or words may be named more quickly if they have been encountered recently. In addition to benefits, however, prior presentation may lead to performance costs. For example, study of a word orthographically or phonologically similar to a target word can lead to errors in perceptual identification of that target (Ratcliff, Albritton, \& McKoon, 1997; Ratcliff \& McKoon, 1996, 1997; Ratcliff, McKoon, \& Verwoerd, 1989). Such findings have led Ratcliff and McKoon to argue that "prior presentation of an item biases processing on subsequent presentations toward a particular response, away from other responses" (1996, p. 405). Patterns of costs and benefits supporting bias interpretations of priming have now been obtained in a number of additional paradigms, including object decision (Ratcliff \& McKoon, 1996), lexical decision (Masson \& Friedman, 1990), word stem completion (Ratcliff \& McKoon, 1996), word fragment completion (Ratcliff \& McKoon, 1996; Smith $\&$ Tindell, 1997), and answering general knowledge questions (Kelley \& Lindsay, 1993), though there is reason to 
believe that not all priming reflects bias effects (see, e.g., Bowers, 1999; Keane, Verfaellie, Gabrieli, \& Wong, 2000; Kinoshita \& Towgood, 2001; Zeelenberg, Wagenmakers, \& Raaijmakers, 2002).

As far as we know, only one investigation has explicitly looked for age differences in both costs and benefits in priming. Light and Kennison (1996) found, with one exception, similar costs and benefits in young and older adults for both single-stimulus and forced-choice word identification tasks. The one exception was a marginally greater tendency in Experiment 1 for young adults to make intrusion errors in single-stimulus word identification. That is, young adults were slightly more prone to respond to a test word (e.g., sage) incorrectly with a previously studied orthographic look-alike (e.g., rage). This pattern suggests a reduced cost for older adults, as assessed by intrusion errors in single-stimulus word identification. In the present article, we report experiments comparing young and older adults on single-stimulus and forced-choice word fragment completion tasks that permit further exploration of the influence of age on both costs and benefits.

In Experiments 1 and 2, a single-stimulus word fragment test was used. Participants were presented with word fragments and were asked to respond with the first word that came to mind that constituted a correct completion. In this paradigm, benefits are revealed in higher fragment completion rates for previously studied words than for new words. Costs are revealed in one of two ways. First, fragment completion rates may be lower for targets with completions that are orthographically similar to studied words than for unrelated targets. Second, studied words may cause intrusions when fragments for words orthographically similar to them serve as targets (Smith \& Tindell, 1997). Although no detailed theoretical mechanisms have been proposed to explain costs and benefits in word fragment completion, these generally have been described in terms of blocking or failure to inhibit currently active, but incorrect, solution candidates (Kinoshita \& Towgood, 2001; Ratcliff \& McKoon, 1996; Smith \& Tindell, 1997).

As we will discuss in more detail in the General Discussion, predictions about potential age differences in costs and benefits depend heavily on the specific mechanisms postulated to underlie these effects. At this juncture, we offer predictions based on three rather different approaches. These are (1) the inhibitory deficit view of Zacks and Hasher (1997), (2) the dual process hypothesis of Kinoshita and Towgood (2001), and (3) bias models of repetition priming.

We take as our jumping off point the postulation of preserved activation and impaired inhibitory processing in old age (Zacks \& Hasher, 1997; Zacks, Hasher, \& Li, 2000). Inhibitory processes are said to be responsible for, among other things, denying working memory access to partially activated but goal-irrelevant information and for suppressing or deleting from working memory once but no longer relevant information. One important consequence of an inhibitory deficit is "an elevated sensitivity to potential sources of interference, both at encoding and retrieval" (Zacks et al., 2000, p. 297). Evidence educed as favoring the inhibition deficit view of cognitive aging includes greater difficulty in ignoring distracting material interspersed in text during reading (Connelly, Hasher, \& Zacks, 1991), an increase in the magnitude of the fan effect in old age (Gerard, Zacks, Hasher, \& Radvansky, 1991), and problems in suppressing the processing of items that are not to be remembered in directed-forgetting tasks (Zacks, Radvansky, \& Hasher, 1996). Inhibition deficit proponents would predict that older adults should show increased costs when there is a strong competitor for the correct completion of a word fragment. This is precisely the situation in our experiments when the test fragment cannot be completed by a recently studied item, but can be completed by an orthographically similar word.

Whether the inhibitory deficit hypothesis predicts equal benefits across age or an age-related decline in benefits is much less clear. If benefits reflect activation over and above bias effects (see Bowers, 1999; Keane et al., 2000; Zeelenberg et al., 2002), and if activation processes are spared in old age, as is suggested by Zacks and Hasher (1997), then it is possible that we would see equal benefits in young and older adults, together with greater costs for older adults. The empirical data are mixed. Light and Kennison (1996) found similar costs and benefits across age in a word identification task (with the one exception noted above). However, a study by Hartman and Hasher (1991) produced a different pattern of results. Young and older participants read sentence frames and predicted the last word of each sentence. For critical sentences, there was a highly predictable final word, but the final word that was presented was a plausible (though less probable) completion for the sentence. The participants were asked to remember the final words that were actually presented. On a subsequent sentence completion task-an indirect measure of memory-young adults showed priming of the presented targets but not of the highly predictable but rejected (and nonpresented) completions. Older adults showed similar levels of priming for the two types of completions - that is, more priming of the rejected target and less priming of the actually presented target than that shown by young adults. This pattern of results was interpreted as evidence that the young, but not the older, adults successfully suppressed the high-probability (but not tobe-remembered) completions. On the basis of Hartman and Hasher's findings, we might predict that in word fragment completion older adults would show reduced priming for actually presented targets along with greater costs, as was described above. However, alternative accounts of this finding that do not invoke inhibition have also been offered (Burke, 1997; Hartman, 1995).

A very different interpretation of costs and benefits in word fragment completion tasks has been offered by Kinoshita and Towgood (2001). These investigators found that, when attention during list study was limited by a concurrent task, benefits (priming) in word fragment completion were unaffected. This finding replicates work of Mulligan and Hartman (1996) and was taken to implicate 
automatic processing. Interestingly, however, costs (measured by a reduction of correct responses after study of orthographically similar words) were eliminated when attention was divided at study. Kinoshita and Towgood argue that this result, which they refer to as a blocking effect, arises from "involuntary aware memory"-namely, spontaneous (but incorrect) recognition of orthographically similar studied words when the word fragments are presented at test. These words then serve as blockers or interlopers that prevent access to correct completions for fragments. Recognition memory is known to be adversely affected by division of attention during study, so involuntary aware memory is less likely when words are studied under divided attention. Any condition, including aging, that lowers recognition should also reduce blocking effects (i.e., costs) in word fragment completion. On this account, we might expect to see lower costs in older adults. If benefits in word fragment completion are produced solely by automatic encoding processes unaffected by aging, then age constancy in these benefits might be expected.

Both the inhibition deficit hypothesis and the Kinoshita and Towgood (2001) account permit costs and benefits to be subserved by different mechanisms. This is not the case for pure bias models such as Ratcliff and McKoon's (1996, 1997) counter model. For instance, the counter model for word identification postulates that studying a word results in that word's representation becoming an attractor basin. During the identification process, the counters for studied words "steal" counts from similar words under certain conditions. Thus, the counts for similar words undergo a reduction, at least on a temporary basis - they are inhibited. The net result is that studied words are better identified than new targets and that orthographically similar words are more poorly identified than new words. That is, costs and benefits go hand in hand. Greater costs should be associated with greater benefits and smaller costs with smaller benefits. A bias model could no doubt be developed for word fragment completion. Such a model would predict that reductions in inhibition should lead to both reduced benefits and reduced costs. Hence, if, as was argued by Zacks and Hasher (1997), aging is accompanied by reduced inhibition, both costs and benefits should show reduction in older adults.

In Experiment 3, we introduced a forced-choice version of the word fragment completion task. ${ }^{1}$ The task we designed is a hybrid of the yes/no word fragment completion task used by Ratcliff and McKoon (1996) and the forced-choice word identification task developed by Ratcliff et al. (1989) and also used in our own studies of bias effects in word identification in young and older adults (Light \& Kennison, 1996). Following list study, participants were tested with a series of word fragments as in Experiments 1 and 2. However, rather than simply generating and producing a word completion, the participants were given $4 \mathrm{sec}$ to generate a fragment and then were asked to choose which of two alternatives, the target or an orthographically similar word, matched the fragment. In this paradigm, benefits are demonstrated by increased ac- curacy when the test fragment can be completed by a previously studied word, and costs are demonstrated by decreased accuracy when the test fragment can be completed by a previously studied word that orthographically resembles the correct completion; both effects are measured relative to a baseline condition in which neither the target nor its orthographically similar companion has been studied. In both the single-stimulus and forced-choice versions of the task, some fragments have competing responses that should be strong because they have recently been studied, and other fragments do not. The two tasks differ only in whether the response requires production (single-stimulus task) or production followed by identification (twoalternative forced-choice task).

The predictions laid out above for the Zacks and Hasher (1997) inhibition deficit hypothesis, for the Kinoshita and Towgood (2001) involuntary recognition hypothesis, and for a pure bias model all should apply equally well to the single-stimulus and forced-choice versions of the word fragment completion task. None of these approaches requires different predictions for different dependent variables. Other considerations, however, suggest that age differences in costs and benefits could be task dependent. Gabrieli and his colleagues(Fleischman \& Gabrieli, 1998; Gabrieli et al., 1994; Gabrieli et al., 1999) note that priming tasks that involve identification of an item or verification of an attribute of an item do not show impairment in Alzheimer's disease, whereas production tasks that demand retrieval from semantic memory (e.g., category exemplar generation) do show impairment (Fleischman \& Gabrieli, 1998).

Classification of tasks into those requiring identification and those requiring production may also prove fruitful in understanding why some studies observe age effects in priming tasks but others do not. In Light et al.'s (2000) meta-analysis, the effect sizes for production and identification tasks were, respectively, $d=0.251$ and $d=0.094$; the confidence interval for identification tasks, but not that for production tasks, included zero. However, most tasks that involve production share another feature-they permit more than a single response at test. This observation suggests an additional dichotomy for priming tasksnamely, whether response competition is high or low at test-and is relevant for theorizing that older adults suffer from a deficit in inhibitory processing. In Light et al.'s meta-analysis, for tasks deemed higher in response competition, $d=0.248$, whereas for those deemed lower in response competition, $d=0.086$. Unfortunately, it is not easy to discriminate between these two classificatory devices, because studies classified as high in response competition tended to be production tasks, whereas those classified as low in response competition tended to be identification tasks. Moreover, the dependent variable in production tasks is typically response probability, whereas in identification tasks it is typically response latency, so there is a confound here as well, and age differences in priming were reliably smaller in the meta-analysis for studies using latency measures. In Experiments 1-3, both production 
and production/identification variants of the word fragment completion task involve response competition when the test fragment can be completed only by a word orthographically similar to that of a studied word. Both variants of the task also use accuracy measures. Thus, Experiments 1-3 permit us to examine the question of whether costs and benefits are both of equal magnitude in young and older adults and whether any age differences that are observed in the pure production version of the task generalize to the production/identification version.

\section{EXPERIMENT 1}

\section{Method}

Participants. Twenty-four young adults (15 men, 9 women) and 30 older adults (14 men, 16 women) participated in Experiment 1. The mean age of the young adults was 20.00 years (range $=18-22$ ), and the mean age of the older adults was 73.57 (range $=67-80$ ). The young participants were undergraduate students from the Claremont Colleges, and the older adults were residents of the Claremont area. Table 1 provides demographic information for the young and older participants in Experiment 1, as well as for those in Experiments 2 and 3 . As is typical in many cognitive aging studies, the older adults scored higher than did the young adults on a vocabulary test (a 25item version of the Nelson-Denny [1960] Vocabulary Test). Age differences in forward and backward digit-span tests, though nonsignificant, favored the young adults. The participants were each paid $\$ 8.00$ for their participation in the research. The data from 8 additional participants, 6 young and 2 older adults, were excluded from the analysis due to equipment failure.

Design and Materials. The experimental materials consisted of 60 word pairs, 48 chosen from Ratcliff and McKoon (1996) and 12 from Smith and Tindell (1997), together with their corresponding fragments (see Appendix). Across all words in these pairs, the mean Francis and Kučera (1982) word frequency was 16.92 (range = $0-491$ ), and mean word length was 7.42 letters (range $=6-9$ ). In addition to the main corpus of experimental words, 32 words and their associated fragments were used as buffer items on the study list, fillers on the test list, and practice items, as described below; the mean frequency of these words was 27.30 (range $=0-408$ ), and their mean length was 6.87 (range $=5-8$ ).

Fragments were created by replacing letters that did not appear in both fragments within a pair with blank spaces, so that what appeared were the same letters that occurred in both words of the pair, but these were sometimes in different positions in the word fragment (e.g., _r $r_{-} m w_{--}$and $r_{-} m_{-} w_{---}$, for tramway and framework, respectively). With the exception of four pairs, ordinal position of letters was the same for the two fragments in a given pair. Two test lists were created. Each test list contained the fragments of one member of each of the 60 fragment pairs (i.e., the fragment for framework appeared in one list and the fragment for tramway appeared in the other). Four filler fragments preceded the 60 experimental fragments; the same fillers were used for both test lists. Of the 60 experimental fragments, 20 could be completed by a word that had been studied, 20 could be completed by a word orthographically similar to a studied word, and 20 were orthographically unrelated to studied words. Order of experimental fragments within a test list was random, with the constraint that no more than three items from a given study condition could appear in a row.

Each study list consisted of 48 words, 4 buffers at the beginning of the list, and 4 buffers at the end, plus 40 experimental words-20 that could be used to complete test fragments (same words) and 20 that were orthographically similar to words that completed test fragments (similar words). Order of experimental words within a study list was random, with the proviso that no more than three words from the same or a similar condition could occur sequentially.

Full counterbalancing of study conditions (same, similar, unstudied) with two test lists required six study lists, three for each test list. Thus, the design of the experiment was 2 (age group: young and older) $\times 3$ (list status: same, similar, unstudied $) \times 2$ (test list). Age and test list were manipulated between subjects, and list status was a within-subjects variable.

Procedure. The participants were tested individually. All materials were presented on a Megaview Ultra VGA monitor controlled by an AT486 computer using Micro Experimental Laboratory (MEL, Version 2.0) software (Schneider, 1995).

At the beginning of the experimental session, each participant gave informed consent and filled out a demographic questionnaire. Next, the study list was presented. Words were presented one at a time in the center of the screen for $5 \mathrm{sec}$ each, with a 100 -msec blank screen between items. The participants were instructed to silently read each word and then to wait for the next word to appear. No mention was made of any forthcoming memory test.

The study phase of the experiment was followed by an unrelated filler task that lasted, on average, between 5 and $7 \mathrm{~min}$. On conclusion of the filler task, the fragment completion test was administered. The participants were instructed to try to generate a word that would complete the fragment and to say it aloud, within the 4-sec time limit. The instructions did not mention any relationship between the words on the study list and the fragments that were to be pre-

Table 1

Demographic Information for the Participants in Experiments 1, 2, and 3

\begin{tabular}{|c|c|c|c|c|c|c|c|c|c|c|c|c|c|c|}
\hline \multirow[b]{3}{*}{ Group } & \multirow{2}{*}{\multicolumn{2}{|c|}{ Age }} & \multirow{2}{*}{\multicolumn{2}{|c|}{ Education $^{\mathrm{a}}$}} & \multirow{2}{*}{\multicolumn{2}{|c|}{ Vocabulary }} & \multicolumn{4}{|c|}{ Digit Spanc } & \multirow{2}{*}{\multicolumn{2}{|c|}{$\underline{\text { Perceptual Speed }}^{\mathrm{d}}$}} & \multirow{2}{*}{\multicolumn{2}{|c|}{ Healthe }} \\
\hline & & & & & & & \multicolumn{2}{|c|}{ Forward } & \multicolumn{2}{|c|}{ Backward } & & & & \\
\hline & $M$ & $S D$ & $M$ & $S D$ & $M$ & $S D$ & $M$ & $S D$ & $M$ & $S D$ & $M$ & $S D$ & $M$ & $S D$ \\
\hline \multicolumn{15}{|c|}{ Experiment 1} \\
\hline Young & 20.00 & 1.47 & 14.38 & $1.41 * *$ & 15.88 & $3.04 * *$ & 6.79 & 1.06 & 5.17 & 1.52 & - & - & 7.88 & 1.30 \\
\hline Old & 73.57 & 4.03 & 16.63 & 2.69 & 21.16 & 3.70 & 6.20 & 1.16 & 5.27 & 1.48 & - & - & 7.60 & 1.85 \\
\hline \multicolumn{15}{|c|}{ Experiment 2} \\
\hline Young & 19.42 & 1.28 & 14.04 & $1.16^{* *}$ & 14.96 & $3.57 * *$ & 7.08 & 1.18 & 5.17 & 1.24 & 35.29 & $6.10 * *$ & 7.46 & 1.69 \\
\hline Old & 72.81 & 4.00 & 16.03 & 2.68 & 21.06 & 2.37 & 6.78 & 1.20 & 5.06 & 1.31 & 29.61 & 7.92 & 8.06 & 1.51 \\
\hline \multicolumn{15}{|c|}{ Experiment 3} \\
\hline Young & 19.71 & 1.43 & 14.50 & $1.32 *$ & 14.83 & $3.80 * *$ & 6.58 & $1.18^{* *}$ & 5.13 & $1.15^{*}$ & - & - & 7.79 & 1.77 \\
\hline Old & 70.50 & 5.13 & 15.96 & 2.73 & 20.00 & 2.98 & 5.54 & 1.18 & 4.33 & 1.01 & - & - & 7.42 & 2.06 \\
\hline
\end{tabular}

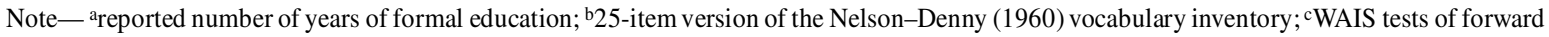

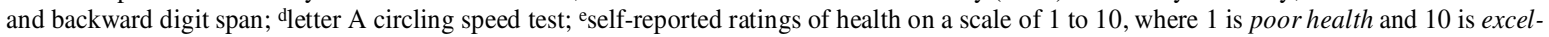
lent health. *Significant difference at $p \leq .05 . \quad * *$ Significant difference at $p \leq .01$. 
Table 2

Mean Proportions of Correct Fragment Completions and Intrusion Errors in Experiment 1

\begin{tabular}{|c|c|c|c|c|c|c|}
\hline \multirow[b]{3}{*}{ Measure } & \multicolumn{6}{|c|}{ Condition } \\
\hline & \multicolumn{2}{|c|}{ Same } & \multicolumn{2}{|c|}{ Similar } & \multicolumn{2}{|c|}{ Unstudied } \\
\hline & $M$ & $S D$ & $M$ & $S D$ & $M$ & $S D$ \\
\hline \multicolumn{7}{|c|}{ Proportion Correct } \\
\hline Young & .306 & .097 & .140 & .087 & .152 & .083 \\
\hline Old & .208 & .097 & .138 & .081 & .140 & .082 \\
\hline Mean & .252 & & .139 & & .145 & \\
\hline \multicolumn{7}{|l|}{ Intrusion Errors } \\
\hline Young & .035 & .045 & .142 & .117 & .054 & .059 \\
\hline Old & .040 & .040 & .103 & .079 & .045 & .044 \\
\hline Mean & .038 & & .120 & & .049 & \\
\hline
\end{tabular}

sented. A 20-item practice test using unrelated items preceded the main word fragment completion test. The participants responded orally, and their responses were recorded by the experimenter. If a response came within the 4-sec time limit, the screen prompted the participant to press the space bar for the next fragment. If the participant did not generate a word within the allotted time, then a "faster please" warning appeared on the screen for $3 \mathrm{sec}$ and was followed immediately by the prompt for the next trial.

Following the test, the participants were queried about their intuitions about the purpose of the experiment and about any strategies they might have used to identify the word fragments. The strategy questionnaire included six questions increasing in specificity from (1) "What do you think was the purpose of the word fragment completion task?" to (6) "When you were not sure what a word fragment was, did you guess words from the study list?"

The participants then completed forward and backward digit-span tasks as well as a 25-item version of the Nelson-Denny (1960) vocabulary test.

\section{Results}

Costs and benefits. Preliminary analysis of the data revealed that the majority of word fragment completions occurred within the 4-sec response window, with only $2.0 \%$ of young adult responses and $2.3 \%$ of older adult responses exceeding this time limit. Analyses with and without responses given after the deadline yielded identical patterns of results; only the former are reported here.

Table 2 provides the mean proportion of correct word fragment completion responses as a function of list status and age. Although both young and older participants correctly completed more previously studied word fragments than new fragments for unstudied words, the young participants received a greater benefit from prior study than did the older adults. A 2 (age group) $\times 3$ (list status: same, similar, unstudied) analysis of variance (ANOVA) confirmed these observations. Overall, the young adults completed more word fragments than did the older adults $\left[F(1,52)=5.77, M S_{\mathrm{e}}=0.0095\right]$. In addition, list status affected fragment completion rates $[F(2,104)=34.46$, $\left.M S_{\mathrm{e}}=0.0068\right]$. However, these effects must be interpreted in the light of a reliable interaction between these factors $\left[F(2,104)=5.49, M S_{\mathrm{e}}=0.0068\right]$.

Two follow-up ANOVAs were carried out to shed light on the interaction between list status and age. The contrast for same and unstudied fragments revealed a benefit for previously studied over new items $\left[F(1,52)=45.95, M S_{\mathrm{e}}=\right.$ 0.0072 ], higher completion rates for the young than for the older adults $\left[F(1,52)=8.97, M S_{\mathrm{e}}=0.0090\right]$, and a greater benefit for the young adults (.154) than for the older adults $\left[.068 ; F(1,52)=6.84, M S_{\mathrm{e}}=0.0072\right]$. [Although small, the benefit for the older adults was significant; $t(29)=3.28$.] The effect size for the age difference in benefits was 0.705 , with a $95 \%$ confidence interval ranging from 0.152 to 1.258 .

The contrast for similar and unstudied items revealed no reliable effects (all $F_{\mathrm{S}}<1$ ). In particular, there was no evidence of an age difference in costs, the computed effect size being 0.093 , with a $95 \%$ confidence interval of -0.444 to 0.630 . However, costs were extremely small, with means of .012 for young adults and .002 for older adults. As will be discussed below, the absence of a cost for similar word fragments was unanticipated.

To investigate the possibility that conscious guessing strategies affected word fragment completion rates, the ANOVAs for costs and benefits were repeated with guessing status included as an additional factor. The participants were deemed to be deliberate guessers if they responded affirmatively to the most pointed of the freeresponse strategy questions, which asked, "When you were not sure what the word fragment was, did you guess words from the study list?" Nine young and 9 older participants were classified as guessers. Means for guessers and nonguessers in each age group were nearly identical. For the young guessers and nonguessers, the means were .289 and $.317, .128$ and .147 , and .144 and .157 for same, similar, and new targets, respectively. For the old guessers and nonguessers, the means were .211 and .207 for same targets, .139 and .138 for similar targets, and .150 and .136 for unstudied targets, respectively. Neither the main effect of guessing nor its interactions with age group or list status were reliable (all $F_{\mathrm{S}}<1$ ). Word fragment completion appears to be insensitive to the use of conscious guessing strategies.

Intrusion errors. The participants sometimes generated the word corresponding to the nonpresented member of a pair (e.g., tramway for framework). As is shown in Table 2, such intrusions occurred more frequently following prior study of similar items than of same or unstudied items, and this was true for both young and older participants. A 2 (age group) $\times 3$ (list status: same, similar, unstudied) ANOVA confirmed these observations. The young and the older participants did not differ reliably in intrusion rates $\left[F(1,52)=1.83, M S_{\mathrm{e}}=0.0045\right]$. List status affected intrusion rates $\left[F(2,104)=23.80, M S_{\mathrm{e}}=0.0047\right]$. The age group $\times$ list status interaction was not reliable $\left[F(2,104)=1.36, M S_{\mathrm{e}}=0.0047\right]$. Nevertheless, because of the suggestion in Table 2 that the young and older adults had nearly identical intrusion rates in the same and unstudied conditions, but that the young adults made more intrusions in the similar conditions, $t$ tests were carried out to compare the young and the older adults in each condition. None was significant, the largest being $t(52)=1.44$ for the similar condition. The effect size for the similar 
condition, however, was a nontrivial 0.388 , with a $95 \%$ confidence interval ranging from -0.154 to 0.930 .

To investigate the possibility that conscious guessing strategies affected the frequency of intrusions, the analyses above were repeated with guessing included as a factor. The main effect of guessing $\left[F(1,50)=3.80, M S_{\mathrm{e}}=\right.$ $0.0042, p=.057]$ was marginally reliable. Overall, the participants who reported guessing made more intrusions than did the nonguessers. For the similar condition, the means were .150 for the guessers (.189 for the young and .113 for the old) and .105 for the nonguessers (.113 for the young and .100 for the old). Although the effect of age seems to be larger for the guessers, with the nonguessers in the two age groups having nearly identical intrusion rates, guessing did not interact with age group $[F(1,50)=$ $\left.2.06, M S_{\mathrm{e}}=0.0042\right]$ or list status $\left[F(2,100)=1.61, M S_{\mathrm{e}}=\right.$ 0.0047 ], nor was the triple interaction reliable $(F<1)$.

\section{Discussion}

Several findings from Experiment 1 are noteworthy. First, some, but not all, aspects of the results replicate those of prior studies demonstrating bias effects in word fragment completion. In particular, like Smith and Tindell (1997) and Ratcliff and McKoon (1996), we observed a benefit (priming) for previously studied words. In addition, like Smith and Tindell, we observed intrusions of previously studied words when the test fragment could be completed correctly by an orthographically similar word but not by the studied word itself. The presence of intrusion errors represents a cost of prior study. Unlike Smith and Tindell (1997) and Ratcliff and McKoon (1996), however, we did not observe a second type of cost-namely, reduced completion probability for fragments that could be completed with words similar to studied words. We suspect that this apparent anomaly arose from the fact that our corpus of fragments, taken as a whole, had low baseline completion rates. Most of our word pairs were taken from Ratcliff and McKoon (1996). In their study, use of a yes/no fragment completion task (with chance performance at .50) would be less likely to show floor effects of the type we observed in our production task.

Second, benefits were present for both the young and the older adults, but they were larger for the young. Some researchers have argued that priming in word fragment completionis immune to the effects of aging (e.g., Winocur, Moscovitch, \& Stuss, 1996) and, indeed, in our own previous work on priming in word fragment completion, age effects were not reliable (Light, Singh, \& Capps, 1986). However, when Light et al. (2000) aggregated the results from five studies comparing priming in word fragment completion in young and older adults, the mean weighted effect size was 0.281 , with a confidence interval of 0.020 0.541 . For Experiment 1, the effect size in benefits was 0.705 . Thus, the evidence argues that Winocur et al.'s conclusion may be premature and that the age difference we observed for word fragment completion priming may be the norm, at least for benefits.

Third, costs did not differ reliably for the young and the older adults, contrary to what might have been expected from response competition or inhibition deficit accounts of cognitive aging. If anything, intrusion errors were somewhat larger for the young adults, although the difference was not statistically reliable. As has been noted above, costs were not visible in completion rates for similar word fragments. We defer further interpretation of these results until those of Experiment 2 have been presented.

\section{EXPERIMENT 2}

The main purpose of Experiment 2 was to provide a replication of Experiment 1. A secondary goal was to explore one possible reason for the greater benefit in word fragment completion for the young adults in that experiment - namely, inadequate time allocated for fragment completion. The time allocated for retrieval in Experiment 1 was $4 \mathrm{sec}$. In Experiment 2, two retrieval durations were used, $3 \mathrm{sec}$ and $10 \mathrm{sec}$. The experimental question was whether, given an extended retrieval period, older adults might show benefits equivalent to those of young adults. Note that the argument here is not that deliberate recollection is used in the word fragment completion task, with young adults engaging in more (or more successful) intentional retrieval and older adults needing more time for this activity; the effects observed in Experiment 1 were the same for the participants who claimed to use strategic retrieval and for those who denied doing so. Rather, the question was whether the rise time for nondeliberate processes might be longer in older adults, who are known to be slower in many cognitive tasks (see Salthouse, 1996, for a review), including resolution of tip-ofthe-tongue states which, like word fragment completion, involve word production (Burke, MacKay, Worthley, \& Wade, 1991).

\section{Method}

Participants. Twenty-four young adults (11 men, 13 women) and 36 older adults (17 men, 19 women) participated in Experiment 2. The mean age of the young adults was 19.42 years (range $=17-22$ ), and the mean age of the older adults was 72.81 (range $=65-81$ ). The young participants were undergraduate students from the Claremont Colleges, and the older adults resided in the Claremont area. On the 25-item version of the Nelson-Denny Vocabulary Test (1960), the older adults had higher scores than the young adults (see Table 1). The two groups did not differ significantly on forward or backward digit span, although, as in Experiment 1, the direction of the small observed differences favored the young. In Experiment 2, a 2-min measure of perceptual speed was administered. The participants were asked to find and circle as many letter As on six sheets of paper as they could in $60 \mathrm{sec}$; each sheet contained a $30 \times 11$ matrix of capital letters. As is indicated in Table 1, the young adults circled significantly more letter As in the allotted time, thereby demonstrating greater speed. The participants received $\$ 8.00$ for their participation. The data of an additional 4 young and 4 older participants were excluded from the analysis. The loss of data of 2 young adults was due to computer malfunction, and the loss of data from the remaining 2 was due to experimenter error. One older participant did not complete the experimental session, and experimenter error accounted for the loss of the remaining 3 older participants' data.

Design and materials. The experimental design was a 2 (age group) $\times 3$ (list status: same, similar, unstudied $) \times 2$ (fragment duration: $3 \mathrm{sec}, 10 \mathrm{sec}$ ) $\times 2$ (duration order: $3 \mathrm{sec}$ preceded by $10 \mathrm{sec}$, 
$10 \mathrm{sec}$ preceded by $3 \mathrm{sec}$ ) mixed factorial. Age group and duration order were between-subjects variables, whereas list status and fragment duration were within-subjects variables. The study and test materials consisted of 60 target words, similar words, and target-wordassociated fragments. Of the 60 experimental word pairs and fragments, 46 were from Ratcliff and McKoon (1996), 10 were from Smith and Tindell (1997), and 4 were generated in our laboratory (4 words were eliminated from the lists used in Experiment 1 to better equate frequency of usage across lists). The corpus of target words (words that were used to generate the fragments) ranged in length from six to eight letters $(M=7.32)$ and had a mean Francis and Kučera (1982) frequency of usage of 10.72 (range $=0-93$ ). The similar words (words that had fragments that were similar to the presented fragment) ranged in length from six to nine letters $(M=7.55)$ and had a mean Francis and Kučera frequency of usage of 9.18 (range $=0-71$ ). The words were divided into six groups of 10 words each, and these six groups were rotated through the 12 cells created by crossing list status, fragment duration, and duration order. In Experiment 2, only one of the two sets of fragments was used to reduce complexity of counterbalancing. In addition to the main corpus of words and fragments, 28 words served as buffers and practice items. These 28 words ranged in length from five to eight letters and had a mean Francis and Kučera frequency of 25.18 (range $=0-408$ ).

The study lists consisted of 48 words (10 same-item-10-secduration words, 10 similar-item-10-sec-duration words, 10 sameitem-3-sec-duration words, 10 similar-item-3-sec-duration words, and 4 buffers at the beginning and 4 at the end of the list). No more than 3 words in a given condition were permitted to occur consecutively.

Each participant received two 32-fragment test lists (two filler items at the beginning of the test and 30 test fragments). One test list was presented in the $10-\mathrm{sec}$ condition, and the other was presented in the 3-sec condition. Each test list was presented in a fixed, random order, with two constraints: (1) the ordering of items by condition for the two test lists was the same, and (2) no more than three words from a single condition appeared in a row. The study and test lists were presented on a Megaview Ultra VGA monitor controlled by an AT486 computer using the MEL (Version 2.0) software.

Procedure. At the beginning of the experimental session, each participant gave informed consent and filled out a demographic questionnaire. The participants were then given the perceptual speed test previously described. Next, the 48-item study list was presented as in Experiment 1. Presentation of the study list was followed by the Trail Making Test, Part B (Reitan, 1992), which took approximately 4 min to complete; the standard instructions were used for this task.

Next, the word fragment completion test was given. The test was divided into two blocks, one presented at the 10-sec rate and one at the 3 -sec rate. Each trial was initiated by a space-bar press. Then, a word fragment appeared in the center of the screen for the specified duration. If the participant made a verbal response before the deadline, the response was immediately followed by a blank screen that appeared for $500 \mathrm{msec}$, followed by the prompt for the participant to initiate the next fragment. If no response was made before the deadline or the response was late, a blank screen appeared for $500 \mathrm{msec}$, followed by the prompt to initiate the next trial. Each block of test trials was preceded by 10 practice trials at the appropriate rate. As in Experiment 1, the instructions made no mention of any relationship between the words on the study list and the word fragments that were to be presented. The participants were instructed to complete word fragments with the "first word that comes to mind" and to say that word aloud.

Following the test, the participants were queried about the strategies they had used to identify the word fragments. The strategy questionnaire was similar to the one used in Experiment 1, but some questions were modified to accommodate the duration variable. There were six free-response questions that ranged in specificity from (1) "What do you think was the purpose of the word fragment completion tasks that you performed?" to (6) "When you were not sure what the word fragment was, did you guess words from the study list?" A small battery of neuropsychological tests was then administered for purposes unrelated to the present discussion; these tests are not described here.

\section{Results}

Costs and benefits. Preliminary analysis revealed that $98 \%$ of the responses of both the young and the older adults fell within the deadlines imposed. The outcomes of ANOVAs including all responses were identical to those including only responses that occurred within deadlines; only the former analyses are reported.

The mean proportions of fragments completed correctly are given in the top panel of Table 3 as a function of age, list status, and fragment duration. Both the young and the older participants completed more fragments for studied words than for unstudied words, but the benefit of prior study was larger for the young than for the older adults. Finally, more word fragments were completed correctly in the 10 -sec condition than in the 3 -sec condition, but the patterns of the means for the two duration conditions were quite similar. A 2 (age group) $\times 3$ (list status: same, similar, unstudied) $\times 2$ (fragment duration: $3 \mathrm{sec}$, $10 \mathrm{sec})$ ANOVA confirmed these observations. The young adults correctly completed more word fragments than did the older adults $\left[F(1,58)=7.49, M S_{\mathrm{e}}=0.020\right]$. Word fragment completion rates varied with list status $[F(2,116)=$ 27.46, $\left.M S_{\mathrm{e}}=0.021\right]$. Participants completed more word fragments in the 10-sec condition than in the 3-sec condition $\left[F(1,58)=6.82, M S_{\mathrm{e}}=0.020\right]$. However, the age and list status effects must be interpreted in the light of a reliable age $\times$ list status interaction $\left[F(2,116)=6.40, M S_{\mathrm{e}}=\right.$ $0.021]$. None of the other two- or three-way interactions was reliable (all $F \mathrm{~s}<1)$.

Table 3

Mean Proportions of Correct Word Fragment Completions and Intrusion Errors for 3-sec and 10-sec Retrieval Conditions in Experiment 2

\begin{tabular}{|c|c|c|c|c|c|c|}
\hline \multirow[b]{3}{*}{ Condition } & \multicolumn{6}{|c|}{ Condition } \\
\hline & \multicolumn{2}{|c|}{ Same } & \multicolumn{2}{|c|}{ Similar } & \multicolumn{2}{|c|}{ Unstudied } \\
\hline & $M$ & $S D$ & $M$ & $S D$ & $M$ & $S D$ \\
\hline \multicolumn{7}{|c|}{ Proportion Correct } \\
\hline $3 \mathrm{sec}$ & & & & & & \\
\hline Young & .313 & .160 & .129 & .095 & .158 & .132 \\
\hline Old & .197 & .121 & .125 & .125 & .156 & .136 \\
\hline Mean & .243 & & .127 & & .157 & \\
\hline \multicolumn{7}{|l|}{$10 \mathrm{sec}$} \\
\hline Young & .367 & .152 & .192 & .141 & .163 & .131 \\
\hline Old & .244 & .140 & .169 & .135 & .181 & .145 \\
\hline Mean & .293 & & .178 & & .173 & \\
\hline \multicolumn{7}{|c|}{ Intrusion Errors } \\
\hline $3 \mathrm{sec}$ & & & & & & \\
\hline Young & .017 & .038 & .100 & .114 & .004 & .020 \\
\hline Old & .028 & .045 & .061 & .077 & .028 & .057 \\
\hline Mean & .023 & & .077 & & .018 & \\
\hline $10 \mathrm{sec}$ & & & & & & \\
\hline Young & .037 & .058 & .088 & .108 & .029 & .055 \\
\hline Old & .033 & .063 & .086 & .083 & .036 & .068 \\
\hline Mean & .035 & & .087 & & .033 & \\
\hline
\end{tabular}


To clarify the nature of the age $\times$ list status interaction, two follow-up analyses were conducted. The contrast comparing same and unstudied items revealed that prior study aided fragment completion $\left[F(1,58)=34.45, M S_{\mathrm{e}}=\right.$ $0.022]$, but the young adults benefited more (.179) than did the older adults $\left[.052, F(1,58)=10.32, M S_{\mathrm{e}}=0.022\right]$. [The benefit for the older adults, though small, was significant at $t(35)=2.08$.] Although somewhat more items were completed in the 10 -sec condition than in the 3 -sec condition $\left[F(1,58)=3.30, M S_{\mathrm{e}}=0.019, p=.07\right]$, fragment duration did not interact with either age or list status, and the triple interaction was not reliable. The mean effect size for the age difference in benefits, averaged over fragment duration, was 0.641 , with a $95 \%$ confidence interval from 0.112 to 1.170 .

The contrast comparing fragment completion for similar and unstudied items revealed no reliable effects (the largest $F=1.50$ for the list status $\times$ duration interaction) except for a marginally reliable main effect of duration $\left[F(1,58)=3.84, M S_{\mathrm{e}}=0.017, p<.06\right]$. The effect size for the age difference in costs was 0.146 , with a $95 \%$ confidence interval from -0.372 to 0.662 . Again, however, costs were very small for both groups, with means of .029 for young adults and .022 for older adults.

To investigate the possibility that conscious guessing strategies affected performance, we recomputed the analyses presented above with guessing included as a factor. Twelve young and 7 older participants reported that they had guessed words from the study list when they were not sure of the fragment. Collapsed across durations, means for the young guessers and nonguessers were .330 and .350 for same targets, .138 and .183 for similar targets, and .154 and .166 for unstudied targets, respectively. For the old guessers and nonguessers, these means were .272 and .209 for same targets, .157 and .145 for similar targets, and .172 and .167 for studied targets, respectively. As in Experiment 1, neither the main effect of guessing nor its interactions with other variables reached conventionallevels of significance. To increase power, we combined the data from Experiments 1 and 2, combining across test durations in Experiment 2, and repeated the analyses of benefits and costs. These analyses confirmed those reported above. In particular, there was no hint of decreased fragment completion in the similar condition for either age group.

Intrusion errors. The mean proportions of intrusion errors are given in Table 3 as a function of age, list status, and fragment duration. Intrusions occurred most often following prior study of similar items and were just slightly more common for the young than for the older participants. A 2 (age group) $\times 3$ (list status: same, similar, unstudied) $\times 2$ (fragment duration: $3 \mathrm{sec}, 10 \mathrm{sec}$ ) ANOVA was carried out. There was no main effect of age $[F(1,58)=$ $\left.0.00, M S_{\mathrm{e}}=0.0074\right]$. A marginally reliable main effect of fragment duration $\left[F(1,58)=3.63, M S_{\mathrm{e}}=0.0035, p=.06\right]$ suggests that somewhat more intrusions were committed in the 10-sec condition than in the 3-sec condition. Most critically, intrusion rates varied with list status $[F(2,116)=$ $\left.26.42, M S_{\mathrm{e}}=0.0048\right]$. The means in Table 3 make it clear that the locus of this effect is in the similar condition; intrusion errors are higher for this condition than for either of the other two. None of the two- or three-way interactions was reliable $(F \mathrm{~s} \leq 1.97)$. For intrusions in the similar condition, $t(58)=1.06$ for age differences; the effect size for age differences was 0.214 , with a $95 \%$ confidence interval from -0.304 to 0.732 .

To see whether deliberate guessing strategies affected intrusion rates, we redid the analyses above with guessing included as a factor. For the most interesting condition, namely intrusions of studied words when similar targets were presented at test, the means for the young guessers and nonguessers, collapsed across durations, were .104 and .084, respectively. For the old guessers and nonguessers, the corresponding means were .064 and .076, respectively. As in Experiment 1, any effect of age appears to be restricted to the guessers, but neither the main effect of guessing nor any interactions involving guessing reached conventionallevels of significance. We also examined intrusions in the similar condition for the combined data of Experiments 1 and 2, collapsing across duration in Experiment 2 , using a 2 (age group) $\times 2$ (experiment) $\times 2$ (guessing) ANOVA. With the increased power gained thereby, the main effect of guessing was not significant $\left[F(1,106)=1.88, M S_{\mathrm{e}}=0.0072, p=.17\right]$, but the main effect of age was $\left[F(1,106)=3.93, M S_{\mathrm{e}}=0.0072, p=.05\right]$. The interaction between age and guessing was not reliable $\left[F(1,106)=1.92, M S_{\mathrm{e}}=0.0072, p=.17\right]$, but it is clear that any age effect here is carried by the guessers, with the young participants' mean $=.141$ and the old participants' mean $=.091$, and the nonguessers having means of .100 for the young and .086 for the old. The safest conclusion here would seem to be that any age difference in intrusions is very small. Notably, there is no evidence of increased intrusions in older adults.

\section{Discussion}

The results of Experiment 2 may be summarized briefly. In all respects, the findings replicated those of Experiment 1 . First, benefits (but not costs) in fragment completion rates were demonstrated for previously presented words. Second, costs were found in intrusions of studied words when the test fragments could be completed only by words that were orthographically similar but not identical to the studied words. Third, older adults again showed a smaller benefit (less priming) than did the younger adults, but they did not demonstrate a greater cost in terms of intrusion rates. In addition, the longer retrieval duration was associated with both somewhat larger completion rates for studied items (benefits) and somewhat greater intrusion rates for the similar condition, but neither of these effects attained conventional levels of significance. Our results are congruent with those of Smith and Tindell (1997, Experiments 5 and 6 ), who also obtained costs with retrieval intervals ranging from $1.5 \mathrm{sec}$ to $10 \mathrm{sec}$ in duration. Of greater importance, age and retrieval duration did not enter into any significant interactions. Thus, the pattern of costs and benefits observed in Experiment 2 for the young 
and the older adults was not moderated by retrieval duration. Although the older adults were slower than the young adults, as evidenced by performance on the circling As task, age differences in benefits were not reduced at the longer test duration.

The joint results of Experiments 1 and 2 present a reasonably clear picture with respect to costs: There were no reliable age differences in intrusion rates in either study taken separately, and only a very small (and difficult-tointerpret) difference, with the young making slightly more intrusions, when the data were combined across experiments. With respect to benefits, the young adults showed more facilitation in word fragment completion than did the older adults. In short, there was no evidence of a differential disadvantage of older adults in a word fragment completion task when there was a strong competitor for the correct solution. These data, then, clearly do not support the Zacks and Hasher (1997) view that inhibition is impaired but activation is spared in old age; this view predicts greater costs for older adults together with equal benefits. Nor are they compatible with Kinoshita and Towgood's (2001) involuntary recognition hypothesis. On that view, we might have expected no age difference in benefits and reduced costs in old age, but that was not the observed outcome. Our data are perhaps most compatible with bias models that predict that costs and benefits will both be affected by the same variables, but the reduction in costs observed in the intrusion data of older adults was very small and its locus appears to be confined to guessers. We are reluctant, then, to argue too strongly for bias interpretations of the data. (We might note, nonetheless, that the reduction in intrusions found for the older adults in Experiments 1 and 2 parallels that observed in single-stimulus word identification [Light \& Kennison, 1996].) Bias models also predict that costs and benefits will be similar in magnitude when they are defined in relation to a new target baseline, but possible floor effects in costs in Experiments 1 and 2 preclude examination of this issue. As we will see, floor effects were not an issue in Experiment 3.

\section{EXPERIMENT 3}

In Experiment 3, we introduced a forced-choice version of the word fragment completion task. As was noted earlier, our task is a hybrid of the yes/no word fragment completion task used by Ratcliff and McKoon (1996) and the forced-choice perceptual identification task developed by Ratcliff et al. (1989). Participants studied a list of words as in our Experiments 1 and 2. On the forced-choice test, a word fragment was presented for $4 \mathrm{sec}$ and was followed by a pair of words, one of which was a correct completion of the fragment and one of which was orthographically similar to it. The participants indicated which of the two words was the correct completion for the fragment. For some test fragments, the correct solution was a word that had been studied. For others, it was a word orthographically similar to a studied word. Finally, for the remaining fragments, there was no corresponding studied word. A benefit in this task is defined as an increase over baseline in correct choices of studied words; a cost is defined as an incorrect choice of a studied word when the test fragment can be correctly completed by a similar word. The experimental questions of interest were whether such effects would be obtained with this new task and, if they were, whether they would be of the same magnitude in young and in older adults.

\section{Method}

Participants. Twenty-four young adults (10 men, 14 women) and 24 older adults (6 men, 18 women) participated in Experiment 3 (see Table 1 for background information). The mean age of the young adults was 19.71 years (range $=18-22$ ) and the mean age of the older adults was 70.50 years (range $=64-83$ ). The young participants were students of the Claremont Colleges, and the older participants were residents of the Claremont area. As in Experiments 1 and 2, the older adults obtained higher scores than did the young adults on the Nelson-Denny 25-item Vocabulary Test (1960). Significant differences were also found in tests of digit span, with the young adults performing better on both forward and backward spans. The participants were each paid $\$ 8.00$ for their participation. The data from 5 additional participants were excluded from analysis. Experimenter error accounted for loss of data from 1 young and 2 older adults; 1 participant fell outside the age ranges established for young and older adults, and 1 young adult had not learned English prior to the age of 7 (our criterion for being considered a native speaker in these experiments).

Design and Materials. The experimental design was a 2 (age group) $\times 3$ (list status: same, similar, unstudied $) \times 2$ (test list) mixed factorial. Age group and test list were between subjects variables, and list status was a within-subjects variable. The assignment of words and word fragments to study and test lists was identical to that described for Experiment 1.

Procedure. The participants were tested individually. All materials were presented via a Dell Pentium GXi computer using MEL (Version 2.0) software.

After the participants had given informed consent and filled out a demographic questionnaire, the study list was presented as in Experiment 1 . Administration of the 25 -item version of the NelsonDenny (1960) Vocabulary Test, a task which took about 5 min, separated the study list from the forced-choice word fragment completion test. Participants received instructions for this test, took a 20item practice test on new items, and then completed the main test; as in Experiment 1, this test consisted of 4 filler fragments followed by the 60 test fragments, 20 from each list status category: same, similar, and unstudied. Each trial began with the presentation of the target fragment on the computer screen for $4 \mathrm{sec}$. The participants were asked to use this time to silently generate a word that matched the fragment. After the fragment disappeared, a pair of alternatives appeared side by side. The participants were to decide which word matched the fragment and to press the " $z$ " key, marked "L" for left, or the " $/$ " key, marked "R" for right, within $1 \mathrm{sec}$ of the onset of the word pair. Although the word pair remained on the screen until a response was made, if the participant did not respond within the 1-sec time limit, a "faster please" warning appeared on the screen for $2 \mathrm{sec}$ after the response. (Our use of a 1-sec deadline was prompted by concerns that participants might engage in deliberate recollection if unlimited response time were permitted [see Ratcliff \& McKoon, 1996, Experiment 4]; as will be seen, however, we were unsuccessful in getting participants to comply fully with the request for speedy responses.) Correct responses alternated randomly between the " $L$ " and " $R$ " keys so that, by the end of the trials, completely correct re- 
Table 4

Mean Proportions of Correct Responses in Two-Alternative Forced-Choice Fragment Completion in Experiment 3

\begin{tabular}{|c|c|c|c|c|c|c|}
\hline \multirow[b]{3}{*}{ Group } & \multicolumn{6}{|c|}{ Condition } \\
\hline & \multicolumn{2}{|c|}{ Same } & \multicolumn{2}{|c|}{ Similar } & \multicolumn{2}{|c|}{ Unstudied } \\
\hline & $M$ & $S D$ & $M$ & $S D$ & $M$ & $S D$ \\
\hline Young & .698 & .116 & .529 & .160 & .594 & .133 \\
\hline Old & .719 & .124 & .556 & .137 & .623 & .103 \\
\hline Mean & .708 & & .543 & & .608 & \\
\hline
\end{tabular}

sponding led to each key's being selected half of the time. After each trial, the participants were prompted to press the space bar for the next fragment.

Following the test, participants were queried about the strategies used on the test, through questions based on the Experiment 1 strategy questionnaire that had been modified for the two-alternative forced-choice paradigm. Finally, the participants completed the forward and backward digit-span tests and were debriefed.

\section{Results}

The response deadline in this experiment was $1 \mathrm{sec}$. It is therefore not altogether surprising that a large proportion of responses fell outside this time limit; fully $20 \%$ of young adult responses and $35 \%$ of older adult responses did so. To avoid loss of data, especially in the older group, we report analyses conducted on the full complement of responses. The pattern of costs and benefits for responses that fell within the deadline was virtually identical to that described below.

Table 4 provides the mean proportions of correct choices as a function of list status and age. The results are quite straightforward. Both the young and the older participants selected the correct alternative more often for word fragments that could be completed with a previously studied word than for word fragments that were associated with unstudied words. However, when confronted with fragments that were associated with a similar studied word, members of both age groups selected the correct alternative less often than they did when fragments were not associated with a studied word. The overall pattern of the means for the two age groups is quite similar. Indeed, a 2 (age group) $\times 3$ (list status: same, similar, unstudied) ANOVA confirmed these observations. The main effect of age group was unreliable $\left[F(1,46)=1.61, M S_{\mathrm{e}}=0.015\right]$. The mean proportions of correct responses varied across list status $\left[F(2,92)=18.59, M S_{\mathrm{e}}=0.018\right]$. Age and list status did not interact $\left[F(2,92)=0.01, M S_{\mathrm{e}}=0.018\right]$, confirming the observation that the young and older adults performed similarly.

Two contrasts were computed to examine costs and benefits. Prior study produced a benefit $[F(1,46)=14.60$, $\left.M S_{\mathrm{e}}=0.016\right]$. Neither the main effect of age nor its interaction with list status was reliable $\left[F(1,46)=1.25, M S_{\mathrm{e}}=\right.$ $0.012 ; F(1,46)=0.02, M S_{\mathrm{e}}=0.016$, respectively]. The mean benefits were virtually identical for the young (.104) and the older (.096) adults. The participants chose the correct alternative less often following study of similar items than of unstudied items $\left[F(1,46)=7.07, M S_{\mathrm{e}}=0.015\right]$, a cost. Neither the main effect of age group $[F(1,46)=0.87$, $\left.M S_{\mathrm{e}}=0.022\right]$ nor its interaction with list status $[F(1,46)=$ $\left.0.00, M S_{\mathrm{e}}=0.015\right]$ was reliable. The mean costs were .065 and .067 for the young and the older participants, respectively. The effect sizes for age differences in priming were $d=0.044,95 \%$ confidence interval $=-0.521$ to 0.621 for benefits, and $d=0.012,95 \%$ confidence interval $=-0.554$ to 0.578 , for costs. Note that the effect sizes for benefits in both Experiments 1 and 2 fall above the upper limit of this confidence interval, indicative of differences in the magnitude of age differences in benefits in the production and production/identification versions of the word fragment completion task.

Nine young and 5 older adults reported that they had guessed words from the study list when they were not sure of the fragment. To investigate the possibility that conscious guessing strategies affected performance, we redid the above analyses with guessing as a factor. There was a list status $\times$ guessing interaction $\left[F(2,88)=6.24, M S_{\mathrm{e}}=\right.$ $0.016]$, but the triple interaction of these factors with age group was not significant $\left[F(2,88)=0.06, M S_{\mathrm{e}}=0.016\right]$. Separate analyses for the guessers and the nonguessers were then carried out. For informational purposes, we give means for the young and old participants combined and for each age group separately to reinforce the lack of interactions between age and guessing status for either costs or benefits. For the guessers, there were reliable benefits [combined $=.215$, young $=.200$, old $=.241 ; F(1,12)=23.70$, $M S_{\mathrm{e}}=0.013$ ] and marginally reliable costs [combined = .081 , young $=.078$, old $=.090 ; F(1,12)=3.26, M S_{\mathrm{e}}=0.014$, $p<.10]$. For the nonguessers, the main effect of item type was reliable $\left[F(2,64)=6.03, M S_{\mathrm{e}}=0.0017\right]$. Benefits (combined $=.053$, young $=.047$, old $=.058)$ and costs (combined $=.059$, young $=.057$, old $=.061$ ) were marginally significant $\left[F(1,32)=3.14, M S_{\mathrm{e}}=0.015, p<.09\right.$ for benefits, and $F(1,32)=3.66, M S_{\mathrm{e}}=0.016, p<.07$ for costs]. The marginality of costs for guessers and of benefits and costs for nonguessers is presumably due to reduced power in these analyses (main effects for costs and benefits reached conventional levels of significance in separate cost and benefit analyses not reported here), and these effects are all significant by one-tailed tests. The crucial point is that in none of the analyses reported above did conscious guessing strategies differentially affect costs or benefits in the young and the old participants on the forcedchoice fragment completion task. ${ }^{2}$

\section{Discussion}

The results of Experiment 3 were unambiguous. In the absence of floor effects, both costs and benefits of prior exposure were demonstrated in the forced-choice word fragment completion task. In addition, these costs and benefits were nearly identical in young and older adults. Thus, there is clear evidence for age constancy in a word fragment completion task that has both production and identification components. Together with the results of Experiments 1 and 2, then, the overall conclusion is that in neither production nor production/identification versions 
of the word fragment completion task do older adults manifest greater costs than young adults in the presence of a strong competitor for the correct completion. Moreover, age differences in benefits were observed in Experiments 1 and 2 only with the pure production version of the task. Implications of these findings are explored in the General Discussion.

\section{GENERAL DISCUSSION}

Our investigations were motivated by two questions, namely (1) whether there are age-related differences in word fragment completion tasks in which the correct solution competes with a recently presented, but incorrect, solution, and (2) whether age-related differences in costs and benefits, if they emerged in a pure production version of the task, would be smaller in a production/identification variant of the task (see Gabrieli et al., 1994; Gabrieli et al., 1999). We begin here by briefly recapitulating the hypotheses outlined in the introduction and evaluating them in terms of the results of Experiments 1-3. We then turn to a further set of theoretical issues raised by our findings.

Our assumption was that orthographically similar competitors would be highly available in our experiments (i.e., activated), at least for the young adults, because they had been studied recently. If activation processes are resistant to impairment with increasing age, whereas inhibitory processes are impaired, as hypothesized by Zacks and Hasher (1997), one prediction is that, in both pure production and forced-choice versions of the word fragment completion task, older adults should show similar benefits (assuming that these result from activation processes) but increased costs (assuming that these arise from inhibitory deficits). According to Kinoshita and Towgood's (2001) dual process view, benefits arise from automatic processes, whereas costs are attributed to spontaneous recognition processes that render incorrect alternatives highly available as blockers. Because recognition is poorer in older than in young adults, the expected pattern would be age constancy in benefits in Experiments 1-3, but reduced costs in the old, again across both variants of the word fragment completion task. Finally, pure bias models (see, e.g., Ratcliff \& McKoon, 1996) would predict a similar pattern of reductions in both benefits and costs across tasks.

Our results are not altogether consistent with any of these scenarios. Although there was evidence in Experiments 1 and 2 for reduced benefits for older adults, there was no indication of greater costs for older adults in either intrusion rates or depressed performance on fragments that could be completed by competing orthographically similar words. In Experiment 3, costs and benefits were virtually identical across age. This combination of results is not consistent with the Zacks and Hasher (1997) inhibition deficit theory, inasmuch as costs were in no case greater for older adults.

Kinoshita and Towgood's (2001) hypothesis also receives little support from the data. Rather than age constancy in benefits across experiments, we observed an age-related drop in benefits in Experiments 1 and 2, although Experiment 3 did show the predicted outcome. With respect to costs, the outcomes of the first two experiments are slightly ambiguous. There was a somewhat smaller number of intrusions in the similar condition for older adults, but this was reliable only when the data from these two studies were combined, and the effect seems largely confined to those who self-report as guessers. Moreover, Experiment 3 gave no evidence of the predicted age-related decline in costs.

Finally, the data do not seem to comport well with pure bias hypotheses. One strength of bias models has been their ability to predict outcomes across different versions of the same task (see, e.g., Ratcliff \& McKoon, 1997). However, the pattern of age differences in costs and benefits was not the same in Experiment 3 as in Experiments 1 and 2. Also, as was discussed above, bias models call for cost reductions when benefit reductions are observed, as in Experiments 1 and 2. However, the evidence for reduced costs in older adults in intrusion rates in the combined analysis of Experiments 1 and 2 is not altogether persuasive and needs replication.

In the remainder of this discussion, we address three issues occasioned by these results. First, we ask at a fairly general level what the locus of costs and benefits might be in the word fragment completion task. Second, we consider the issue of whether it is necessary to postulate inhibitory mechanisms to explain the results. And, third, we consider the ramifications of these findings for theories of cognitive aging.

As was noted earlier, finding depressed word fragment completion accuracy or increased intrusions in similartarget conditions has been described as due to blocking by, or imperfect inhibition of, competing response alternatives (Ratcliff \& McKoon, 1996; Smith \& Tindell, 1997). Following Anderson and Bjork (1994), Smith and Tindell suggested four possible loci for these effects: (1) executive control processes, (2) cue bias, (3) associative bias, and (4) target bias.

In several experiments, Smith and Tindell (1997)asked participants (all of whom were young) to actively avoid recalling primes. One version of the executive control bias hypothesis (Anderson \& Bjork, 1994) would posit that deliberate avoidance of primes could lead to depressed performance, because participants may use a more conservative response criterion for both correct and incorrect solutions. However, even with very specific instructions to avoid primes, costs were observed, suggesting that these costs cannot be due exclusively to failures of executive control at a conscious level. Our experiments do not directly address this issue. However, costs and benefits were obtained for participants who denied deliberately guessing previously studied words and those who claimed to be doing so, and this finding, too, argues against a large role for executive processes in the paradigm used here.

According to Anderson and Bjork (1994), cue bias models deal with the "selection of the units or cues at which 
activation is initiated" (p. 285). In the context of word fragment completion tasks, cue bias refers to a tendency to incorrectly encode the word fragment at test in the similar condition (Smith \& Tindell, 1997). That is, on some proportion of trials with similar target fragments, participants may misperceive these similar target fragments, mistakenly identifying them as derived from studied words. On such trials, the participants then incorrectly generate the studied word and give it as a response in production tasks or choose it when the alternatives appear in the two-alternative forced-choice variant of the task, thereby yielding a cost of prior exposure. (This formulation appears to be consistent with the idea of the automatic retrieval of orthographically similar primes referred to by Kinoshita \& Towgood, 2001.) Alternatively, the participants might simply maintain a representation of the incorrectly perceived test fragment and then match that representation to the two word alternatives, choosing the best fit for this representation.

In a follow-up study, we tested the cue bias hypothesis in the context of the two-alternative forced-choice task. Thirty young adults, drawn from the same population as those tested in Experiments 1 to 3, studied words under the same conditions as those used in Experiment 3. For each trial on the forced-choice test, a word fragment appeared in the center of the screen for $4 \mathrm{sec}$. The participants were instructed to use this time to silently generate a word that matched the fragment. The presentation of the word fragment was followed by two alternatives, presented side by side. On half of the trials, the alternatives were words, and on the other trials they were fragments. The two types of alternatives were randomly intermixed across the trials so that, on each trial, the participants could not predict whether words or fragments would appear. On trials in which words appeared, the participants were instructed to choose the word that correctly completed the previously presented word fragment. On trials in which fragments appeared, the participants were instructed to choose the fragment that matched the previously presented word fragment.

When the test alternatives were words, there was a reliable benefit in identification for same items and a marginally reliable cost $(p<.10)$ for similar items; the proportions of correct choices were $.680, .500$, and .567 for same, similar, and new test fragments, respectively. However, when the test alternatives were word fragments, neither benefits nor costs were evident; the proportions of correct choices were $.640, .673$, and .657 for same, similar, and unstudied fragments, respectively. Our interpretation of this set of results is that costs do not arise from misperceiving the target fragments in the similar condition. If they had, we would expect to find that the pattern of results was the same when the test alternatives were fragments and when they were words. However, it is clear that there are costs and benefits for word alternatives, but that performance does not vary across same, similar, and new conditions for fragment alternatives. Although this study does not directly address the issue of fragment perception in the pure production version of the task, there is no a priori reason to suppose that the situation should be different in the two variations of the word fragment completion paradigm.

According to Anderson and Bjork (1994), executive control bias, cue bias, and associative response bias can lead to inhibition-like phenomena without changes in the underlying representations of competing responses. The discussion above should make it clear how this can occur for executive control and cue biases. In the case of associative bias in word fragment completion tasks, in the similar condition a previously studied word would incorrectly be retrieved as a solution for the target fragment. However, the representation of the correct solution would not have its activation level lowered. Rather, it is the increased activation of studied words or cue-target pathways that accounts for both benefits and costs. To see how this might work here, imagine that the letters $r, m$, and $w$ have prior connections with the orthographic representations of both tramway (the correct solution) and framework (an incorrect solution). ${ }^{3}$ Studying tramway strengthens the connections between $r, m, w$, and tramway but leaves unchanged the connections between these letters and framework. The probability of producing a particular response to the test fragment $r_{-} m_{-} w_{---}$is a function of the strength of the fragment-word association for that response (determined by the strengths of the connections of the individualletters to the word), relative to the sum of all fragment-word associations. Presenting tramway boosts its fragment-word associative strength without lowering the strength of the connection between $r_{-} m_{-} w_{--}$and framework. However, the increase in strength of the fragment-word association for tramway effectively lowers the likelihood that framework will be produced correctly after tramway has been studied. The same mechanism explains the elevated rate of tramway intrusions to the $r_{-} m_{-} w_{-}{ }_{--}$fragment without invoking inhibitory mechanisms. Similar proposals have been made to account for neighborhood effects in spoken word recognition (Goldinger, Luce, \& Pisoni, 1989), for effects of priming semantic competitors in picture naming (Wheeldon \& Monsell, 1994), and for lexical access in speech production (Levelt, Roelofs, \& Meyer, 1999). 4

Such explanations can be quite difficult to distinguish empirically from explanations based on inhibition or suppression of competing responses, which Anderson and Bjork (1994) refer to as target bias. As was noted earlier, bias effects in word fragment completion have been referred to as inhibitory effects (Ratcliff \& McKoon, 1996) or as blocking effects (Smith \& Tindell, 1997). However, it is important to distinguish between what Dell and O'Seaghdha (1994) called inhibition at "a molar level of behavioral description that is often synonymous with interference" (p. 409), or competition of responses, and inhibition as "a molecular, quasi-neural process by which representational units send inhibitory signals to one another, or regulate their own activation by self-inhibition" (Dell \& O'Seaghdha, 1994, p. 409). For instance, in Ratcliff and McKoon's $(1996,1997)$ counter model, bias ef- 
fects in perceptual identification arise from inhibition at a theoretical level. The counter model postulates that studying a word results in of that word's representation becoming an attractor basin. During the identification process, the counters for studied words "steal" counts from similar words under certain conditions. Thus, the counters for similar words undergo a change, at least on a temporary basis, qualifying the model as an inhibition theory. Similar models presumably could be developed for costs and benefits in word fragment completion tasks, but to date they have not been. In the word fragment completion experiments reported here, for both the pure production and the production/identification tasks, costs and benefits on a behavioral level look like inhibitory phenomena. Our results, nonetheless, do not permit us to decide between inhibitory and noninhibitory theoretical explanations.

These considerations have important implications for cognitive aging theory. Burke (1997) argued forcefully that age differences in behavior that look like response competition effects cannot be unambiguously attributed to the construct of inhibition as defined within the context of carefully articulated theoretical models. In the present experiments, we obtained clear evidence for competitionlike phenomena-intrusions of studied words as incorrect fragment completions in the first two experiments and costs in the forced-choice task in the third. However, we saw but scant evidence for interactions of these effects with age.

Does this mean that we should conclude that older adults do not suffer from an inhibitory deficit? Unfortunately, although our results are reasonably clear on an empirical level, without a clearer understanding of the mechanisms underlying costs and benefits in word fragment completion priming, we cannot make strong inferences from behavior to the theoretical constructs used to explain that behavior. Our results (reduced benefits and similar or slightly lower intrusion rates in single-stimulus word fragment completion, similar costs and benefits in forcedchoice word fragment completion) are not consistent with Zacks and Hasher's (1997) view that activation is spared in old age, whereas inhibition is impaired. A simple interpretation in terms of either activation or inhibition processes, such as those sketched above, however, is also complicated by the asymmetry of age effects observed for production and verification versions of the word fragment completion task. Both would predict that older adults should have reduced costs if they have reduced benefits, and both would predict similar effects for the two versions of the task that we used. For instance, inhibition models similar in concept to Ratcliff and McKoon's (1997) counter model for word identification produce benefits by suppressing representations of similar items, so reduced inhibitory processes should produce both lower benefits and lower costs. Although the older adults did show reduced costs, their intrusions rates, though lower in Experiments 1 and 2 than those of the young adults, were just slightly significantly lower. And, in Experiment 3, with a forcedchoice procedure, age effects were negligible. At present, then, there appears to be no straightforward theoretical interpretation of our results. They do, nonetheless, provide answers to the empirical questions with which we began: There is no persuasive evidence for increased competition effects in repetition priming for older adults in either production or identification tasks.

\section{REFERENCES}

Anderson, M. C., \& BJork, R. A. (1994). Mechanisms of inhibition in long-term memory. In D. Dagenbach \& T. H. Carr (Eds.), Inhibitory processes in attention, memory, and language (pp. 265-325). San Diego: Academic Press.

BowERS, J. S. (1999). Priming is not all bias: Commentary on Ratcliff and McKoon (1997). Psychological Review, 106, 582-596.

Burke, D. M. (1997). Language, aging, and inhibitory deficits: Evaluation of a theory. Journals of Gerontology: Psychological Sciences, 52B, P254-P264.

Burke, D. M., MacKay, D. G., Worthley, J. S., \& Wade, E. (1991). On the tip of the tongue: What causes word finding failures in young and older adults? Journal of Memory \& Language, 30, 542-579.

CoHen, J. (1988). Statistical power analysis for the behavioral sciences. Hillsdale, NJ: Erlbaum.

Connelly, S. L., Hasher, L., \& Zacks, R. T. (1991). Age and reading: The impact of distraction. Psychology \& Aging, 6, 533-541.

Dell, G. S., \& O'Seaghdha, P. G. (1994). Inhibition in interactive activation models of linguistic selection and sequencing. In D. Dagenbach \& T. H. Carr (Eds.), Inhibitory processes in attention, memory, and language (pp. 409-453). San Diego: Academic Press.

Fleischman, D. A., \& Gabrieli, J. D. E. (1998). Repetition priming in normal aging and Alzheimer's disease: A review of findings and theories. Psychology \& Aging, 13, 88-119.

Francis, W. N., \& KuČERA, H. (1982). Frequency analysis of English usage: Lexicon and grammar. Boston: Houghton Mifflin.

Gabrieli, J. D. E., Keane, M. M., Stanger, B. Z, KJelgaard, M. M., Corkin, S., \& Growdon, J. H. (1994). Dissociations among structuralperceptual, lexical-semantic, and event-fact memory systems in Alzheimer, amnesic, and normal subjects. Cortex, 30, 75-103.

Gabrieli, J. D. E., Vaidya, C. J., Stone, M., Francis, W. S., ThompsonSchill, S. L., Fleischman, D. A, Tinklenberg,J. R., Yesavage, J. A., \& Wilson, R. A. (1999). Convergent behavioral and neuropsychological evidence for a distinction between identification and production forms of repetition priming. Journal of Experimental Psychology: General, 128, 479-498.

Gerard, L., Zacks, R. T., Hasher, L., \& Radvansky, G. A. (1991). Age deficits in retrieval: The fan effect. Journals of Gerontology: Psychological Sciences, 46, P131-P136.

Goldinger, S. D., Luce, P. A., \& Pisoni, D. B. (1989). Priming lexical neighbors of spoken words: Effects of competition and inhibition. Journal of Memory \& Language, 28, 501-518.

Hartman, M. (1995). Aging and interference: Evidence from indirect memory tests. Psychology \& Aging, 10, 659-669.

Hartman, M., \& HASher, L. (1991). Aging and suppression: Memory for previously relevant information. Psychology \& Aging, 6, 587-594.

Keane, M. M., Verfaellie, M., Gabrieli, J. D. E., \& Wong, B. M. (2000). Bias effects in perceptual identification: A neuropsychological investigation of the role of explicit memory. Journal of Memory \& Language, 43, 316-344.

Kelley, C. M., \& LindSAY, D. S. (1993). Remembering mistaken for knowing: Ease of retrieval as a basis for confidence in answers to general knowledge questions. Journal of Memory \& Language, 32, 1-24.

Kinoshita, S., \& Towgood, K. (2001). Effects of dividing attention on the memory-block effect. Journal of Experimental Psychology: Learning, Memory, \& Cognition, 27, 889-895.

LA VoIE, D. J., \& Light, L. L. (1994). Adult age differences in repetition priming: A meta-analysis. Psychology \& Aging, 9, 539-553.

Levelt, W. J. M., Roelofs, A., \& Meyer, A. S. (1999). A theory of lexical access in speech production. Behavioral \& Brain Sciences, 22, 1-75. Light, L. L., \& KenNison, R. F. (1996). Guessing strategies, aging, and 
bias effects in perceptual identification. Consciousness \& Cognition, 5, 463-499.

Light, L. L., Prull, M. W., La Voie, D. J., \& Healy, M. R. (2000). Dual-process theories of memory in old age. In T. J. Perfect \& E. A. Maylor (Eds.), Models of cognitive aging (pp. 238-300). New York: Oxford University Press.

Light, L. L., SingH, A., \& CAPPS, J. L. (1986). Dissociation of memory and awareness in young and older adults. Journal of Clinical \& Experimental Neuropsychology, $8,62-74$.

Masson, M. E. J., \& Friedman, L. (1990). Fluent identification of repeated words. Journal of Experimental Psychology: Learning, Memory, \& Cognition, 16, 355-373.

McClelland, J. L., \& Rumelhart, D. E. (1981). An interactive activation model of context effects in letter perception: Part 1. Psychological Review, 88, 375-407.

Mulligan, N. W., \& Hartman, M. (1996). Divided attention and indirect memory tests. Memory \& Cognition, 24, 453-465.

Nelson, M. J., \& Denny, E. C. (1960). The Nelson-Denny reading test (rev. by J. I. Brown). Boston: Houghton Mifflin.

Ratcliff, R., Albritton, D., \& McKoon, G. (1997). Bias in auditory priming. Journal of Experimental Psychology: Learning, Memory, \& Cognition, 23, 143-152.

Ratcliff, R., \& McKoon, G. (1996). Bias effects in implicit memory tasks. Journal of Experimental Psychology: General, 125, 403-421.

Ratcliff, R., \& McKoon, G. (1997). A counter model for implicit priming in perceptual word identification. Psychological Review, 104, 319-343.

Ratcliff, R, McKoon, G., \& Verwoerd, M. (1989). A bias interpretation of facilitation in perceptual identification. Journal of Experimental Psychology: Learning, Memory, \& Cognition, 15, 378-387.

ReITAN, R. M. (1992). Trail Making Test: Manualfor administrationand scoring. South Tucson, AZ: Reitan Neuropsychology Lab.

Salthouse, T. A. (1996). The processing-speed theory of adult age differences in cognition. Psychological Review, 103, 403-428.

SCHNEIDER, W. (1995). MEL Professional, Version 2.0. Pittsburgh: Psychology Software Tools.

Smith, S. M., \& Tindell, D. R. (1997). Memory blocks in word fragment completion caused by involuntary retrieval of orthographically related primes. Journal of Experimental Psychology: Learning, Memory, \& Cognition, 23, 355-370.

Verhaeghen, P., Marcoen, A., \& Goossens, L. (1993). Facts and fiction about memory aging: A quantitative integration of research findings. Journals of Gerontology: Psychological Sciences, 48, P157-P171.

Verhaeghen, P., \& SAlthouse, T. A. (1997). Meta-analyses of agecognition relations in adulthood: Estimates of linear and nonlinear age effects and structural models. Psychological Bulletin, 122, 231-249.

WHEeldon, L. R., \& Monsell, S. (1994). Inhibition of spoken word production by priming a semantic competitor. Journal of Memory \& Language, 33, 332-356.

Winocur, G., Moscovitch, M., \& STuss, D. T. (1996). Explicit and implicit memory in the elderly: Evidence for double dissociation involving medial temporal- and frontal-lobe functions. Neuropsychology, 10, 57-65.

ZACKS, R. \& HASHER, L. (1997). Cognitive gerontology and attentional inhibition: A reply to Burke and McDowd. Journals of Gerontology: Psychological Sciences, 52B, P274-P283.

ZACKS, R. T., HASHER, L., \& Li, K. Z H. (2000). Human memory. In F. I. M. Craik \& T. A. Salthouse (Eds.), The handbook of aging and cognition (2nd ed., pp. 293-357). Mahwah, NJ: Erlbaum.

Zacks, R. T., RAdVANSKY, G., \& HASHeR, L. (1996). Studies of directed forgetting in older adults. Journal of Experimental Psychology: Learning, Memory, \& Cognition, 22, 143-156.

Zeelenberg, R, Wagenmakers, E.-J. M., \& Raaijmakers, J. G. W. (2002). Priming in implicit memory tasks: Prior study causes enhanced discriminability, not only bias. Journal of Experimental Psychology: General, 131, 38-47.

\section{NOTES}

1. A two-alternative forced-choice word fragment completion task identical to ours was independently developed by Zeelenberg et al.(2002).

2 . In previous research, we found that only guessers demonstrated reliable costs and benefits in a forced-choice perceptual identification task (Light \& Kennison, 1996). The present results argue against the generality of statements that bias effects in all forced-choice priming tasks are the result only of deliberate guessing.

3. One objection to this account might be that letter-word associations are position specific (see, e.g., McClelland \& Rumelhart, 1981), so that a word fragment containing letters that appear in different positions in different words should activate only those words that share letters in identical positions with the fragment. Because target words and their orthographically similar counterparts were not invariably of the same length and did not always share letters in identical positions, costs and benefits might not be predicted by theories that confine interactive effects to letters in identical positions within words.

4. This is not the only possible account of costs and benefits that does not invoke inhibition. For instance, Bowers (1999) has argued that bias effects in forced-choice perceptual identification arise due to priming of the test alternatives themselves. An extension to the word fragment completion task is straightforward. If participants simply ignore the test fragments, they might pick the studied alternative preferentially because of increased activation. This would, of course, produce a benefit when the test fragment completes a studied word, and a cost otherwise. This explanation would not, however, work well for the production task. 
APPENDIX

Words and Word Fragments Used in Experiments 1-3

The following word pairs served as stimulus materials in Experiments 1-3. For each word, the uppercase letters appeared in the word fragment.

\begin{tabular}{|c|c|c|c|c|c|}
\hline tRaMWay & HiSToRy a,b & oUtSidER & fLaMInGo & CHARiTya & doWAGer \\
\hline fRaMeWork & HolSTeR & crUSadER & cLiMbInG & CHARTer & seWAGe \\
\hline CROqUet & cYlinDeR & hElPFul & fRaNtiC & rePrieVE & iNsoMNiA \\
\hline CROUpier & bYstanDeR & lEaPFrog & aRseNiC & caPtiVE & pNeuMoNiA \\
\hline sPItTlE & vICeROyd & liQUiDs & IIQUors $^{\mathrm{d}}$ & mYstIqUe & uRetHRa \\
\hline oPIaTEs & hICkORy & aQUeDuct & seQUoIa & sYmposIUm & bRetHRen \\
\hline FaIlUREa & oUtFOx & pEtUNIa & cAsHmeREd & eQualizE & AlLerGYa \\
\hline FIxtURE & bUfFalO & dEbUNkIng & cAtHetER & sQueeZE & AnaLoGY \\
\hline PhoENiX & maVeriCK & fiLTraTE & aFfOrDed & sUrVivaL & rHoMBuS \\
\hline aPpENdiX & liVestoCK & aLTernaTE & daFfODil & jUVeniLe & cHaMBerS \\
\hline sCiSsoRs & cOcOnUT & CUlPriT $^{\mathrm{a}}$ & SIliCoNb & TaNGenT $^{\mathrm{a}}$ & GLiTtEr ${ }^{c}$ \\
\hline aCceSsoRy & wOrkOUT & CrUmPeT & SICiliaN & ToNiGhT & GLisTEn \\
\hline eVEninGs & $\mathrm{bEGoNIa}^{\mathrm{d}}$ & aARdVArk & DigNITYa $^{a}$ & 1EtTUCe & tASteFuL ${ }^{c}$ \\
\hline aVEraGe & 1EGIoNs & cARaVAn & DeNsITY & kEnTUCky & bAShFuL \\
\hline caLYpsO & CoUnTRy ${ }^{\mathrm{a}, \mathrm{b}}$ & meMBraNE & hYbRiD & sQUaSh & $\mathrm{KEYnotE}^{\mathrm{c}}$ \\
\hline baLlYhoO & ClUsTeR & seMBlaNcE & mYRiaD & eQUalS & KEYstonE \\
\hline VOltAGEa & qUaRtET & CaTAloGa $^{\mathrm{a}}$ & sAPPhIre & chIMNeY & $\operatorname{diCTiON}^{c}$ \\
\hline VOyAGEr & laUREaTe & CoTtAGe & APPetIte & alIMoNY & friCTiON \\
\hline hiGhWAy & leNGtHs & cOntEXts & disCOVer & $\mathrm{BaGgAgE}^{\mathrm{a}}$ & \\
\hline meGaWAtt & diNGHy & anOrEXia & alCOVes & BriGAdE & \\
\hline luKewaRM & TRaGedYa & bLaRNEy & frIDaYs ${ }^{b}$ & rHEtORic & \\
\hline hooKwoRM & TRiloGY & cLaRiNEt & acIDitY & tHEORies & \\
\hline
\end{tabular}

Note- aPairs from Smith and Tindell (1997). bPairs used in Experiments 1 and 3 but not in Experiment 2. cPairs used in Experiment 2 only. dFragments with swapped letters. 